\title{
PEMANFAATAN KAYU BAKAU (Rhizopora sp.) SEBAGAI PONDASI RUKO DI KECAMATAN TEMBILAHAN DAN KORELASINYA TERHADAP KELESTARIAN HUTAN MANGROVE DI KABUPATEN INDRAGIRI HILIR
}

\author{
Aldryandes Novriandra ${ }^{1}$, Evi Sribudiani' ${ }^{2}$, Rudianda Sulaeman ${ }^{2}$ \\ ${ }^{1}$ Alumni Program Studi Kehutanan, Fakultas Pertanian Universitas Riau \\ ${ }^{2}$ Staf pengajar Program Studi Kehutanan, Fakultas Pertanian Universitas Riau \\ Jl. Binawidya Km. 12.5, Simpang Panam,Pekanbaru 28293 Riau \\ Telp.(0761) 78901, Fax.(0761) 45678 \\ Email: aldryandes.novriandra@gmail.com, sribudiani@yahoo.co.id, \\ rudianda1974@gmail.com
}

\begin{abstract}
The purpose of this research was toknowed utilization mangrove tree (Rhizopora sp.) as foundation of shophouse and correlation to preservation mangrove forest in Indragiri Hilir Regency. Primary data is interview to know number of needs mangrove tree in unit area, source, and management mangrove wood in Tembilahan Subdistrict, Indragiri Hilir Regency. Secondary data is building lisence and extensive of mangrove forest in Indragiri Hilir Regency. Amount average requirement mangrove wood in an unit is 1500 stem with wood's diameter 5 inch $\quad(10,2 \mathrm{~cm})$ and length $7 \mathrm{~m}$. Analysis use pearson correlation between requiment of mangrove wood as shophouse foundation in Tembilahan subdistrict and exetensive of mangrove forest and get ccorrelation coefficient was -0.54. it categories in medium class and don't same direction. Based signification test show value 0,477 and mean is both variable is not significant
\end{abstract}

Keywords : mangrove wood, foundation, shophouse 
PENDAHULUAN

\section{Latar Belakang}

Kecamatan

sebagai pusat pemerintahan dan perdagangan di Kabupaten Indragiri Hilir menjadikan kecamatan tersebut sebagai kecamatan yang potensial untuk mendirikan ruko agar usaha yang akan dijalankan dapat lebih menguntungkan dalam hal aksesibilitas. Letak kecamatan yang berada strategis dan pemukiman masyarakat yang tinggi menjadi nilai tambah dalam keinginan untuk mendirikan ruko.

Pembangunan ruko di Kabupaten Indragiri Hilir, khususnya di Kecamatan Tembilahan telah menjadi suatu tren dalam pembangunan tempat tinggal. Ruko merupakan titik keseimbangan antara dua kepentingan yakni kebutuhan tempat tinggal dan tempat dalam perdagangan barang atau jasa pada satu lahan yang sama yang digunakan masyarakat pada umumnya. Ruko terdiri atas minimal dua tingkat atau lebih dengan lantai dasar sebagai tempat usaha dan lantai atas sebagai tempat tinggal. Bangunan yang bertingkat ini tentunya memerlukan persiapan yang matang dalam pembangunan agar bangunan dapat tetap kokoh, salah satunya perencanaan pondasi ruko.

Keadaan tanah yang berupa lempung menyebabkan perlu adanya rekayasa teknik pondasi untuk mendapatkan bangunan kokoh untuk jangka panjang, yang dapat menyangga beban bangunan tersebut dan pencegahan terhadap keretakan bangunan bahkan penurunan bangunan. Pada kondisi tanah di Kabupaten Indragiri hilir, dilakukan pondasi dalam yang dapat menyangga dari lapisan tanah yang keras. Salah satu jenis pondasi yang digunakan dalam 
pembangunan ruko di Kabupaten Indragiri Hilir adalah kayu bakau yang ditancapkan ke dalam tanah hingga terbenam keseluruhan.

Sifat kayu bakau yang cocok menjadikan bakau sebagai pondasi di Kabupaten Indragiri Hilir. Seiring meningkatnya pembangunan ruko di Kabupaten Indragiri Hilir, tentu akan meningkatkan kebutuhan akan kayu bakau setiap waktunya. Namun dengan pertumbuhan bakau yang tidak sesuai dengan jumlah permintaan bakau akan dapat menyebabkan eksploitasi terus-menerus dan merusak ekosistem di hutan mangrove yang berfungsi sebagai pencegahan abrasi, intrusi air laut dan sebagainya.

Semakin

meningkatnya

pembangunan di Kabupaten Indragiri Hilir tentunya akan meningkatkan permintaan bakau sebagai pondasi dasar dalam pembangunan tersebut. Disisi lain, keberadaan mangrove di Kabupaten Indragiri Hilir terus mengalami kerusakan seperti konversi lahan dan penebangan secara tidak berkelanjutan yang akan menyebabkan terjadinya kelangkaan akan kebutuhan kayu bakau sebagai pondasi dalam pembangunan ruko.

Menurut Hilmi

(2010),

ekosistem

mangrove

di

Kabupaten Indragiri Hilir merupakan suatu ekosistem utama yang harus dipertahankan keberadaannya. Namun sangat disayangkan bahwa tingkat kekritisan ekosistem mangrove di Indragiri Hilir sangat tinggi dimana dari luas ekosistem mangrove $121.535,31$ ha, areal mangrove rusak seluas $66.355,11$ ha dan ekosistem rusak berat 55.180,19 ha atau dapat dikatakan seluruh areal mangrove di Indragiri Hilir berada dalam kategori rusak $(54,60 \%)$ dan rusak berat $(45,40 \%)$. 
Tingginya tingkat kekritisan mangrove dapat disebabkan oleh beberapa faktor diantaranya eksploitasi yang berlebihan. Eksploitasi mangrove berkaitan dengan kebutuhan bahan baku. Untuk itu perlu dikaji bagaimana dan sejauh mana pemanfataan kayu bakau sebagai pondasi ruko.

Tujuan dari penelitian ini adalah untuk mengetahui pemanfaatan bakau sebagai pondasi ruko dan korelasinya terhadap kelestarian hutan di Kabupaten Indragiri Hilir.

\section{BAHAN DAN METODE}

Penelitian ini dilakukan di Kecamatan Tembilahan, Kabupaten Indragiri Hilir, Provinsi Riau. Alat yang digunakan pada penelitian berupa : kamera, alat tulis, alat perekam, laptop dengan aplikasi terpasang SPSS 17. Bahan yang digunakan adalah daftar pertanyaan.
Data dan informasi yang dikumpulkan terdiri dari data primer dan data sekunder. Data primer didapatkan untuk mendapatkan informasi tentang penggunaan kayu bakau sebagai pondasi pembangunan ruko.

Dalam penelitian ini, data sekunder yang digunakan adalah

a. Data sebaran hutan mangrove Kabupaten Indragiri Hilir (Sumber : Balai Pemantapan Kawasan Hutan Wilayah XIX Pekanbaru).

b. Data Izin Mendirikan Bangunan (IMB) Kabupaten Indragiri Hilir (Sumber; Badan Perizinan dan Penanaman Modal dan Promosi Daerah Kabupaten Indragiri Hilir).

Pengumpulan data dilakukan dengan wawancara dan observasi. Metode wawancara digunakan untuk mengetahui jumlah kebutuhan bakau sebagai pondasi dalam satuan luas pembangunan dan mengetahui 
sumber bakau didapat.

Wawancara dilakukan kepada informan penelitian dengan pedoman yang telah dibuat. Informan dalam wawancara ini adalah semua penjual kayu bakau, pekerja bangunan pondasi ruko di Kecamatan Tembilahan, dan Dinas Kehutanan Kabupaten Indragiri Hilir. Observasi yang dilaksanakan berupa pengamatan pola penggunaan kayu bakau sebagai pondasi dalam pembangunan ruko.

Pengolahan data dalam penelitian ini dilakukan dengan cara :

1. Menghitung jumlah bakau yang dibutuhkan sebagai pondasi dalam bangunan ruko.

2. Menghitung jumlah kebutuhan bakau sebagai pondasi ruko yang dibangun dalam satu tahun di Kecamatan Tembilahan, Kabupaten Indragiri Hilir.

\section{Analisis Data}

Analisis data dilakukan dengan melakukan analisis korelasi kebutuhan bakau pada Kecamatan Tembilahan dengan kelestarian mangrove di Kabupaten Indragiri Hilir.

Kuat tidaknya hubungan antara $X$ dan $Y$ apabila dapat dinyatakan dengan fungsi linear (paling tidak mendekati), diukur dengan suatu nilai yang disebut koefisien korelasi. Jadi jika $r=$ koefisien korelasi, maka nilai $r$ dapat dinyatakan sebagai berikut.

$$
-1 \leq r \geq 1
$$
Artinya :

Jika $r=1$, hubungan $\mathrm{X}$ dan $\mathrm{Y}$ sempurna dan positif (mendekati 1, yaitu hubungan sangat kuat dan positif)

$=-1$ hubungan $\mathrm{X}$ dan $\mathrm{Y}$ sempurna dan negatif (mendekati 1, yaitu hubungan sangat kuat dan negatif)

$=0$, hubungan $X$ dan $Y$ lemah sekali atau tidak ada hubungan. 
Cara menghitung $r$ adalah sebagai berikut.

$$
r=\frac{n \sum X Y-\sum X \sum Y}{\sqrt{n \sum X^{2}-\left(\sum X\right)^{2}} \sqrt{n \sum Y^{2}-\left(\sum Y\right)^{2}}}
$$

HASIL DAN PEMBAHASAN

Kondisi

Umum

Penelitian

Kabupaten Indragiri Hilir merupakan kabupaten terluas di Provinsi Riau. Luas Kabupaten Indragiri Hilir mencapai 11.605,97 $\mathrm{Km}^{2}$. Secara Geografis Kabupaten Indragiri Hilir terletak dibagian selatan Provinsi Riau dengan letak antara $0^{\circ} 36^{\prime}$ Lintang Utara dan $1^{\circ} 07^{\prime}$ Lintang Selatan, dan antara $104^{\circ} 10^{\prime}$ Bujur Timur dan $102^{\circ} 32^{\prime}$ Bujur Timur.

Sebagian besar (93,31\%) dari luas wilayah Kabupaten Indragiri Hilir merupakan daerah endapan sungai serta daerah rawa dengan tanah gambut (peat) berupa hutan payau (mangrove) yang meliputi pesisir sungai Indragiri dan pulau-pulau dengan luas lebih kurang
1.082.953,06 hektar dengan ratarata ketinggian lebih kurang 0-3 Meter dari permukaan laut. Hanya sebagian kecil wilayah $(6,69 \%)$ berupa daerah berbukitbukit dengan ketinggian rata-rata 6-35 meter dari permukaan laut, yang terdapat dibagian selatan Sungai Reteh Kecamatan Keritang, yang berbatasan dengan Propinsi Jambi.

Pada umumnya struktur tanah di Kabupaten Indragiri Hilir terdiri atas tanah Organosol (Histosil), yaitu tanah gambut yang banyak mengandung bahan organik. Tanah ini dominan di Wilayah Indragiri Hilir terutama daratan rendah diantara aliran sungai. Sedangkan disepanjang aliran sungai umumnya terdapat formasi tanggul alam natural river leves yang terdiri dari tanah-tanah 
Alluvial (Entisol) dan Gleihumus (Inceptisol).

\section{Kebutuhan kayu bakau sebagai pondasi ruko}

Kayu

bakau

yang dimanfaatkan sebagai pondasi ruko dibutuhkan rata-rata 1500 batang untuk setiap satuan unit ruko. Dimensi rata-rata ruko yang dibangun adalah 4x17 meter. Jumlah kebutuhan rata-rata ini sama antara ruko dengan jumlah lantai yang berbeda, baik itu dua sampai empat lantai.

Kriteria kayu yang digunakan sebagai pondasi yakni memiliki panjang kurang lebih 7 meter dengan diameter pangkal kayu 4 inchi $(10,2 \mathrm{~cm})$. Kriteria ini didasarkan pada pengalaman para pekerja yang khusus dalam mengerjakan pondasi ruko dan rancangan kerja yang telah dibuat.

Dimensi ini sesuai dengan penelitian Hermawan menyatakan bahwa panjang tiang optimum sebagai pondasi adalah 7 meter. Penambahan panjang tiang mempengaruhi faktor aman daya dukung dan faktor aman gaya lateral. Semakin panjang tiang yang dipakai semakin besar faktor amannya. Menurut Suroso dkk (2008) semakin besar diameter dan panjang kayu bakau sebagai pondasi secara keseluruhan memberikan peningkatan daya dukung. Menurut Mulia dan Sumardjani (2001) riap kayu bakau agar mencapai dimensi diameter 10,2 cm dan tinggi 7 membutuhkan waktu 7 tahun dengan jarak tanam $2 \times 2 \mathrm{~m}$.

Tabel 1. Kebutuhan Kayu Bakau sebagai pondasi ruko di Kecamatan Tembilahan

\begin{tabular}{ccc}
\hline Tahun & Jumlah Ruko (Unit) & $\begin{array}{c}\text { Kebutuhan Bakau Rata-Rata } \\
\text { (Batang) }\end{array}$ \\
\hline 2010 & 132 & 198.000 \\
2012 & 98 & 147.000 \\
2014 & 63 & 94.500 \\
\hline
\end{tabular}

Sumber : Data Olahan Tahun 2015 
Harga satu batang kayu bakau yang digunakan untuk pondasi ruko adalah Rp. 13.500 Rp. 15.000. yang dijual di bangsal kayu di Kecamatan Tembilahan. Jika dikalikan dengan satu unit ruko maka dibutuhkan hingga $\mathrm{Rp}$ 22.500.000 untuk memenuhi pembuatan pondasi ruko.

Keuntungan penggunaan kayu sebagai pondasi adalah; kayu relatif ringan dibandingkan beton atau baja, sehingga mudah dalam transportasi, kekuatan tarik besar sehingga pada waktu penangkatan untuk pemancangan tidak menimbulkan kesulitan seperti pada tiang pancang precast, mudah untuk pemotongannya apabila tiang kayu ini sudah tidak masuk lagi ke dalam tanah, tiang pancang kayu atau cerocok lebih sesuai/baik untuk friction pile daripada end bearing pile sebab tegangan tekanannya relatif kecil, dan karena pondasi kayu relatif fleksibel dan lenting terhadap arah horizontal dibandingkan dengan tiang-tiang pancang selain kayu, maka apabila tiang ini menerima beban horizontal yang tidak tetap, tiang kayu akan melentur dan segera kembali ke posisi setelah beban horizontal tersebut hilang. (Ardiansyah, 2010).

Asal pembelian kayu bakau untuk pembangunan ruko dari bangsal kayu yang berada di Kecamatan Tembilahan dan Tembilahan Hulu. Bangsal ini biasanya menjual kayu bakau dengan berbagai ukuran sesuai tujuan penggunaan, misalnya untuk pondasi ruko, pondasi rumah, dan kontruksi bangunan. Semakin besar beban kontruksi bangunan yang akan dibuat, dimensi kayu bakau yang dibutuhkan akan semakin besar. 


\section{Pemanfaatan Kayu Bakau di} Kecamatan Tembilahan

Pengusahaan kayu bakau di Kecamatan Tembilahan bersifat ilegal karena tidak memiliki dokumen yang sah dalam pemungutan dan pengangkutan hasil hutan. Hal ini diakui Kepala Bidang Pemanfaatan Hutan Dinas Kehutanan Kabupaten Indragiri Hilir. Pemungutan hasil hutan ini paling banyak dilaksanakan di Kecamatan Mandah, Kecamatan Kuala Indragiri, Kecamatan Concong, Kecamatan Tanah Merah, dan Kecamatan Kateman. Dari hasil yang diambil secara ilegal ini diangkut dan dijual di Kabupaten Indragiri Hilir, bahkan sampai Indragiri Hulu dan Malaysia.

\section{Berdasarkan} penelitian Rosmardi (2004), faktor yang menyebabkan tingginya pengambilan kayu bakau secara ilegal adalah tingkat pendapatan dan umur. Semakin tinggi pendapatan akan dapat mengurangi peluang untuk mengambil kayu bakau. Selain itu, semakin tinggi umur (usia produktif) maka peluang untuk mengambil kayu bakau semakin besar karena semakin berpengalaman dan semakin terbiasa untuk melakukan pengambilan kayu bakau.

Dalam pemungutan hasil hutan yang ilegal, Dinas Kehutanan Kabupaten Indragiri Hilir sudah mengupayakan dalam penyidikan kasus ini. Namun terdapat kendala dalam penyidikan kasus pemanfaatan kayu bakau secara ilegal yakni tidak adanya dana operasional untuk pengamanan kayu bakau yang diambil oleh masyarakat. Dana ini meliputi biaya transportasi untuk melakukan patroli sebagai tindakan pencegahan dan juga untuk biaya penyidikan yang dilakukan oleh pegawai Dinas Kehutanan 
Kabupaten Indragiri Hilir terhadap terhadap kasus pemungutan dan pengangkutan kayu bakau.

Penyebaran Mangrove di Kabupaten Indragiri Hilir

Data penyebaran hutan mangrove di Kabupaten Indragiri Hilir diperoleh dari Balai Pemantapan Kawasan Hutan Wilayah XIX Pekanbaru. Data ini

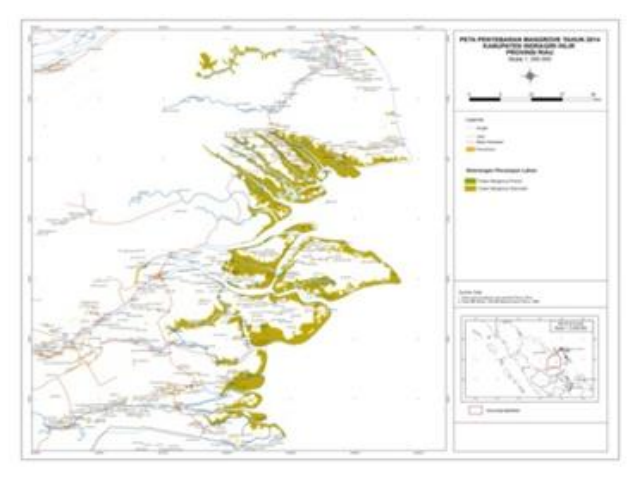

Gambar 1. Peta Penyebaran Mangrove di Kabupaten Indragiri Hilir dianalisis berdasaran penafsiran citra pada tahun 2011-2014.

Terdapat kendala dalam penafsiran hutan mangrove di Indragiri Hilir yakni sebagian wilayah ini sering ditutupi oleh awan dan membutuhkan biaya operasional yang besar untuk melakukan cek lapangan langsung karena berada sebagian besar berada pada wilayah perairan.

Hutan mangrove di Kabupaten Indragiri Hilir terdapat pada beberapa kecamatan antara lain Kecamatan Mandah, Kecamatan Kuala Indragiri Hilir, Kecamatan Concong, Kecamatan Sungai Batang, Kecamatan Reteh, Kecamatan Pelangiran, dan Kecamatan Kateman. Kecamatan-kecamatan ini berada pada muara sungai yang merupakan kondisi yang cocok untuk jenis mangrove dapat tumbuh. 
Tabel 2. Luas Hutan Mangrove di Kabupaten Indragiri Hilir

\begin{tabular}{cc}
\hline Tahun & Luas Hutan Mangrove (Ha) \\
\hline 2009 & $101.525,72$ \\
2011 & $100.403,05$ \\
2012 & $100.250,52$ \\
2013 & $100.232,51$ \\
\hline
\end{tabular}

Sumber : Balai Pemantapan Kawasan Hutan Wilayah XIX Pekanbaru

Korelasi Jumlah Kebutuhan Ruko di Kecamatan Tembilahan dan Luas Penyebaran Hutan Mangrove Di Kabupaten Indragiri Hilir

Setelah dilakukan analisis korelasi pearson antara jumlah kebutuhan bakau sebagai pondasi ruko dan luas hutan mangrove di Kabupaten Indragiri Hilir tahun 2009, 2011, 2012, dan 2013 diketahui memiliki hubungan yang cukup kuat, yakni -0,52. Koefisien korelasi ini menunjukkan kekuatan hubungan linear dan arah hubungan dua variabel.

Berdasarkan pedoman interpretasi koefisiesn korelasi maka nilai -0,523 termasuk dalam kategori sedang.

Tanda negatif pada koefisien korelasi artinya hubungan antara kedua variabel adalah tidak searah. Artinya dengan semakin meningkatnya nilai kebutuhan kayu bakau sebagai pondasi ruko, maka variabel luas hutan mangrove di Kabupaten Indragiri Hilir akan menurun. Didasarkan pada kriteria yang ada,hubungan kedua variabel tidak signifikan karena angka signifikasi sebesar 0,477>0,05.

Hubungan yang cukup kuat ini bisa disebabkan oleh pemungutan yang dilakukan di mangrove, sehingga koefisien korelasi tergolong dalam kategori cukup. Penyebab lainnya adalah adanya program rehabilitasi lahan yang dilakukan Dinas Kehutanan Kabupaten Indragiri Hilir yang membuat pengurangan luas 
penutupan pada hutan mangrove masih dapat dikendalikan.

Semakin tingginya pembangunan ruko ke depannya menjadi meningkat, membuat resiko pengurangan luas tutupan lahan, lebih khusus lagi terhadap hutan lindung yang menyangga kehidupan masyarakat di Kabupaten Indragiri Hilir. Solusi yang dapat dilaukan untuk mengurangi resiko tersebut adalaha perlu adanya tindakan sistem pengelolaan mangrove, khususnya kayu bakau, berbasis masyarakat yang memiliki legalitas hukum untuk mengelola dan memanfaatkan lahan yang telah ditentukan agar mampu mengurangi penguragan luas hutan di Kabupaten Indragiri Hilir. Selain itu, masih adanya macammacam pondasi alternatif selain menggunakan kayu bakau, seperti pancang tiang beton (paku bumi) dan lain sebagainya.

\section{KESIMPULAN DAN SARAN}

\section{Kesimpulan}

a. Jumlah rata-rata kebutuhan kayu bakau sebagai pondasi untuk satu unit ruko adalah 1500 batang.

b. Jumlah kebutuhan kayu bakau sebagai pondasi ruko dan pengurangan luas hutan lindung di Kabupaten Indragiri Hilir memiliki koefisien korelasi dalam kategori sedang yakni $\quad-0,523$ tidak searah dan hubungannya tidak signifikan.

\section{Saran}

Perlu penelitian lebih lanjut tentang solusi pengelolaan kayu bakau oleh masyarakat di Kabupaten Indragiri Hilir agar pemanfaatan hutan mangrove dapat terlaksana secara baik. 


\section{DAFTAR PUSTAKA}

Hilmi, E. 2010. Analisis Biodiversity Ekosistem Mangrove di Indragiri Hilir. Di dalam prosiding Seminar Nasional Biologi Biodiversitas dan Bioteknologi Sumberdaya Akuatik. Fakultas Biologi Onsoed. Purwokerto.

Hermawan, R. Surjandari, N. S. As'ad, S. 2014. Analisis Perkuatan Tanah pada dasar Tanggul Sungai Gajah Putih Surakarta dengan Cerucuk Kayu. E-Jurnal Matriks Teknik Sipil, Volume 2 Nomor 1.

Suroso. Harimurti. Harsono, M. 2008. Alternatif Perkuatan Tanah Lempung Lunak (soft clay) menggunakan cerucuk dengan variasi panjang dan diameter cerucuk. Jurnal
Rekayasa Sipil Volume 2 Nomor 1.

Mulia, F. Sumardjani, L. 2001. Hutan Tanaman Mangrove : Prospek Masa Depan Kehutanan Indonesia. Kongres Kehutanan Indonesia III. Jakarta.

Rosmardi. 2004. Pemberdayaan Masyarakat Sekitar Hutan Dalam Rangka Mengatasi Pengambilan Kayu Bakau Secara ilegal di Kabupaten Indragiri Hilir. Sekolah Pasca Sarjana Institut Pertanian Bogor. Bogor.

Ardiansyah, R. 2010. Menyoal Kelayakan Cerocok Kayu. https://ronymedia.wordpress. com/2010/05/29/menyoalkelayakan-cerocok-kayu. Diakses tanggal 2 Agustus 2015. 